\title{
Utilisation of Home Laundry Effluent (HLE) as a catalyst for expeditious one-pot aqueous phase synthesis of highly functionalised 4-thiazolidinones
}

\author{
Udaya Pratap Singh ${ }^{1,3^{*}}$, Hans Raj Bhat ${ }^{1}$, Mukesh Kumar Kumawat ${ }^{2}$ and Ramendra K Singh ${ }^{3^{*}}$
}

\begin{abstract}
Background: The impact of global warming and associated climate changes have built up pressure to focus on the option of green chemistry over traditional one for long term sustainability of the environment. Considering the fact, for the first time, efficient HLE catalysed expeditious one-pot synthesis of highly functionalised 4-thiazolidinones has been developed.

Results: These hybrid molecules were synthesized in good to excellent yields. The ease of work-up of the reactions less time required and mild conditions are notable features of this protocol. It was inferred that halogen containing derivatives were well suited to this condensation-cyclization reaction with varying rates to afford 4-thiazolidine derivatives. In general, the substitution on the aldehyde part was shown as a main determinant for reaction time and the product yield.

Conclusion: For the first time home laundry effluent (HLE) owing to the surfactant like property has been successfully utilised as catalyst for the synthesis of a series of novel 4-thiazolidinone derivatives through one pot, three component condensation-cyclization reaction. The uniqueness of the present protocol lies in the operational simplicity, ability to reduce the demand for organic solvents, reduce the energy and carbon footprint, and meet a wide range of economic needs.
\end{abstract}

Keywords: Home laundry effluent; One-pot synthesis; 4-thiazolidinones

\section{Background}

The design, synthesis and development of novel heterocyclic scaffolds of pharmacological importance have fascinated both organic as well as medicinal chemists. Among from the established heterocyclic pharmacophores, 4thiazolidinone derivatives are deemed to be of considerable importance due to their wide array of biological properties. These derivative posses various pharmacological actions, for instance, antibacterial (Zevzikoviene et al. 2012), antiHIV (Rawal et al. 2005), antifungal (El Bialy et al. 2011), anticonvulsants (Siddiqui et al. 2010), follicle stimulating hormone (FSH) receptor agonist activity (Wrobel et al.

\footnotetext{
* Correspondence: udaysingh98@gmail.com; singhramk@rediffmail.com 'Department of Pharmaceutical Sciences, Sam Higginbottom Institute of Agriculture Technology and Sciences, Formerly Allahabad Agricultural Institute, Deemed to be University, Allahabad 211007, India

${ }^{3}$ Nucleic Acids and Antiviral Research Laboratory, Department of Chemistry, University of Allahabad, Allahabad 211002, India

Full list of author information is available at the end of the article
}

2006), anti-inflammatory activity (Eleftheriou et al. 2012), anticancer (Havrylyuk et al. 2011), etc. Besides, they are also utilised as chemical antecedents for many compounds, for example polymethine cyanine dyes (El-Aal 2003). More recently, these derivatives were used in the synthesis of pyrazolothiazole derivatives (Turgut et al. 2007) and monofluoro- $\beta$ lactams (Fuchigami et al. 1992). Consequently, number of protocols have been developed and reported for the synthesis of 4-thiazolidinone including one-step, two-step or via one-pot multicomponent reactions (Kumar et al. 2013). The one-pot multicomponent reactions to synthesize these nuclei offer several advantages and are preferred over traditional synthesis because of their ability to synthesize small drug-like molecules in efficient manner by virtue of minimal workup, high atom economy and being highly modular with several degrees of structural diversity (Orru \& de Greef 2003). The reaction involved in synthesis of thiazolidinone proceeds via formation of schiff base intermediate at the initial followed 


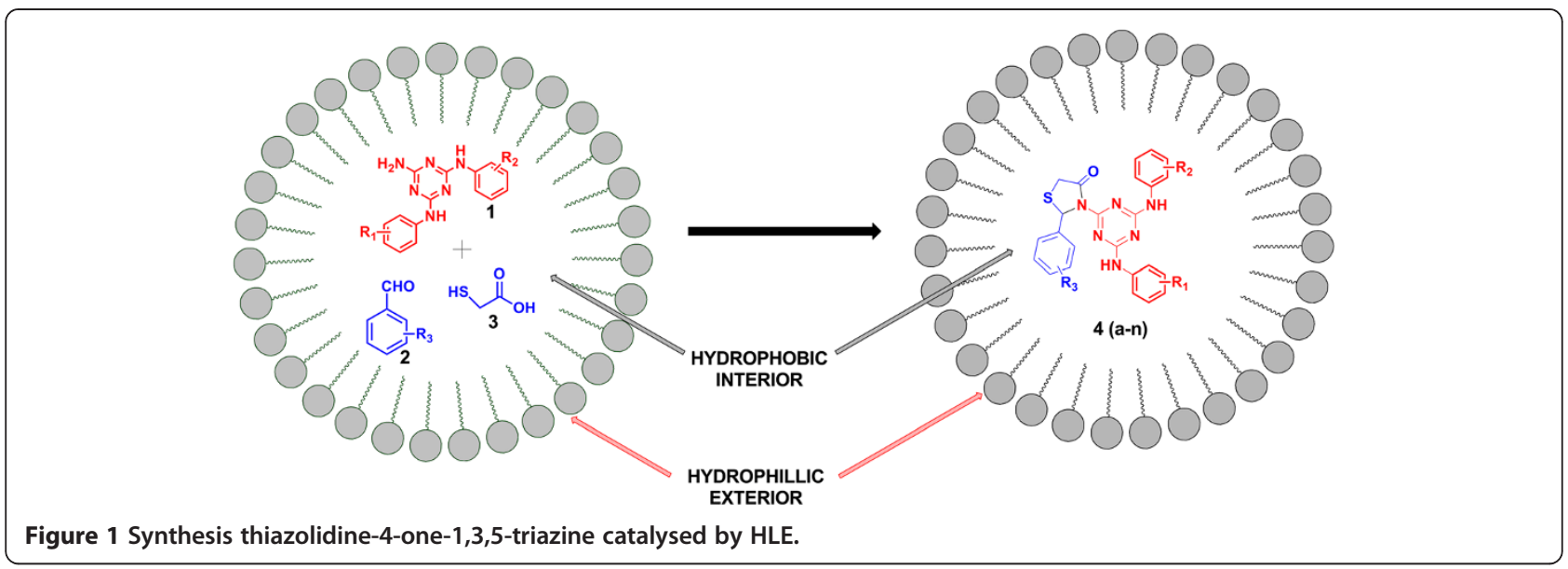

by an attack of a sulphur nucleophile, a mercaptocarboxylic acid, resulting in intermolecular cyclization and eviction of water to yield the desired product (Bolognese et al. 2004). However, removal of the water in the last step is presumably believed as a rate determining step and considered to be critical for obtaining the 4-thiazolidinediones in high yields. As a result, several strategies have been developed for removal of the in situ generated of water for efficient yield of the target molecules. Most commonly followed protocols for water removal involve azeotropic distillation using a Dean Stark trap with either benzene or toluene as solvent medium, molecular sieves and dehydrating agent like DCC (N,N'-Dicyclohexylcarbodiimide) (Tierney 1989; Surrey 1947).

However, the conventional protocols for the synthesis of 4-thiazolidinedione have been associated with numerous shortcomings including the use of perilous solvents, expensive catalysts, long work-up procedures, harsh reaction conditions, in-efficient atom economy, and generation of the by-products. More recently, commercially available surfactant $p$-dodecylbenzenesulfonic acid (DBSA) has been reported for synthesis of 2,3-di substituted 4thiazolidinones derivatives (Prasad et al. 2012). Thus, there has been an urgent need to develop a benign,

Table 1 Catalytic activity evaluation for reaction ${ }^{\text {a }}$

\begin{tabular}{llllc}
\hline Entry & Type of surfactant & Catalyst load & Time (h) & \% Yeild \\
\hline 1 & HLE & 0 & \multicolumn{2}{c}{ No reaction } \\
2 & HLE & 5 & 56 & 10 \\
3 & HLE & 10 & 50 & 25 \\
4 & HLE & 15 & 44 & 51 \\
5 & HLE & 20 & 40 & 66 \\
6 & HLE & 25 & 28 & 89 \\
7 & HLE & 50 & 20 & 76
\end{tabular}

HLE Home laundry effluent.

${ }^{\mathrm{a}}$ Reaction conditions: amine $(0.01 \mathrm{~mol})$, aldehyde $(0.01 \mathrm{~mol})$, thioglycolic acid (0.01 mol).

${ }^{\mathrm{b}}$ Isolated and unoptimised yields. eco-friendly and inexpensive protocol for the synthesis of 4-thiazolidinone derivatives.

The environmental imbalances have compelled us to adopt the concept of green chemistry in our modern day researches. The green chemistry is a philosophy of chemical research that encourages the design of products and processes that minimize the use and generation of hazardous substances. It aims to protect the environment by inventing new chemical processes that do not pollute, rather than by cleaning up (2012). Water is the most abundant and environmental friendly solvent available in nature and the organic reaction performed in it gained significant attention owing to its various advantages, viz. low cost, safety and environment friendly nature (Dunn 2010). Yet its application in organic synthesis is limited as most organic substrates have poor solubility in water (Shapiro \& Vigalok 2008). A good number of strategies have been devised to solve this problem by creating the organic micro-environment in aqueous phase by using surfactants, organic co-solvents or hydrophobic auxiliaries (Lindstrom 2002). On another hand reaction catalysed by surfactants are considered environment benign and are preferred over others (Zhao et al. 2011). Albeit, owing to eco-friendly approach showed by surfactants, its high cost is a major limiting factor for the reactions to be carried out. Therefore, development of novel solvent system which has surfactant like properties at minimal cost is more viable option. Prompted from these ideas, we tried to utilise the surfactant like properties of home laundry effluent (HLE) to catalyse the reactions (Ariel, a laundry detergent (washing powder)). The HLE is categorised as a type of greywater generated from household on washing clothes and has been disposed off in the open environment causing environment pollution. It is entirely different from more heavily contaminated "black water" from toilets. Greywater can be of far higher quality than black water because of its low level of contamination and higher potential for reuse (Allen et al. 2010). Further, use of HLE 
Table 2 Effect of temperature on the reaction ${ }^{\mathrm{a}}$

\begin{tabular}{llll}
\hline Entry & Temp & Time $(\mathbf{h})$ & Yield $^{\mathbf{b}}$ \\
\hline 1 & Room temperature $^{c}$ & 37 & 21 \\
2 & 45 & 25 & 95 \\
3 & 60 & 18 & 73 \\
4 & 80 & 12 & 54 \\
\hline
\end{tabular}

Reaction conditions: amine $(0.01 \mathrm{~mol})$, aldehyde $(0.01 \mathrm{~mol})$, thioglycolic acid (0.01 mol).

b Isolated and unoptimised yields.

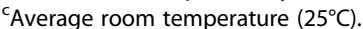

as reaction media has ability to reduce the demand for organic solvents, reduce the energy and carbon footprint, and meet a wide range of economic needs. This surfactant rich effluent possibly catalyses the reactions through the same way as a surfactant did and provides a greener way of synthesis with economic viability in comparison to the expensive surfactants.

The hybridisation of different pharmacophores in single chemical entity is gaining attraction from the medicinal chemists owing to its synergistic or addition effects, enlarged spectrum of action, less prone to spontaneous mutation and resistance development and possibility of dual drug targeting at more than one site (Morphy \& Rankovic 2005). 1,3,5-Triazine, an important heterocyclic scaffold has been found to possess variety of pharmacological activities, such as antibacterial (Gahtori \& Ghosh 2012), anti-HIV (Lozano et al. 2011), antifungal (Singh et al. 2012a), antimalarial (Bhat et al. 2013), and anticancer (Bekircan et al. 2005). The hybridisation of this bioactive heterocyclic moiety with another pharmacophores is a matter of investigation of our research programme and till now we have reported numerous hybrid conjugates of 1,3,5-triazine with thiazole (Singh et al. 2011), piperazine (Ghosh et al. 2012), 1,3-thiazine (Singh et al. 2012b) and 1,3,4-thiadiazole (Dubey et al. 2012) as antimicrobial agents.

In continuation of our research endeavour on facile synthesis of novel heterocyclic scaffolds, herein, we report a mild and expeditious aqueous phase one pot synthesis of highly functionalised 4-thiazolidinone incorporated 1,3,5-triazine derivatives catalysed by HLE in moderate to excellent yields, Figure 1 .

\section{Results and discussion}

Studies have been carried out to observe the effect of various concentrations of HLE on the reaction as well as its effect on the product yield. As depicted in Table 1, reactions were carried out with and without HLE (blank) at room temperature. The equimolar quantity of amine $\left(N^{2}, N^{4}\right.$-bis(3-fluorophenyl)-1,3,5triazine-2,4,6-triamine), aldehyde (2-chlorobenzaldehyde) and thioglycolic acid were taken as model substrates in the presence of $25 \mathrm{~mol} \%$ of HLE as catalyst at room temperature for $28 \mathrm{~h}$. Surprisingly, a buff white powder of 4f was obtained in $89 \%$ yield. It was also revealed that no product was formed in the absence of HLE under the same reaction condition, whereas a $5 \mathrm{~mol} \%$ of catalyst load resulted in poor yield (10\%) even after a prolonged reaction time of $56 \mathrm{~h}$. On further increment of catalyst load to $10 \mathrm{~mol} \%$, the product yield was enhanced (25\%) in shorter time of $50 \mathrm{~h}$. It is noteworthy that two-fold increase in product yield (4f) accompanied by shorter reaction time was observed on increasing the catalyst load to $15 \mathrm{~mol} \%$. A continuous notable shift in product yield (66\%) as well as reduction in reaction time $(40 \mathrm{~h})$ was observed at the $20 \mathrm{~mol} \%$ of HLE. As a matter of fact, increase in product yield was accompanied by decreased reaction time under the same reaction condition on each increment of catalytic load till $20 \mathrm{~mol} \%$ with maximum at $25 \mathrm{~mol} \%$, which demonstrated the positive catalytic role of HLE in the synthesis of 4-thiazolidinone. On further increment of catalytic load to $50 \mathrm{~mol} \%$, the yield of desired product was decreased to $76 \%$.

The next phase of the study was aimed to determine the effect of temperature on the reaction. Increasing the temperature, although favoured the cyclization process but did not result in increased product yield. However, an optimum yield of the desired product was obtained at $45^{\circ} \mathrm{C}$, Table 2, Figure 2.

After optimizing the conditions for cyclization, we intended to determine its scope and limitations for synthesizing hybrid molecules using substituted aldehydes

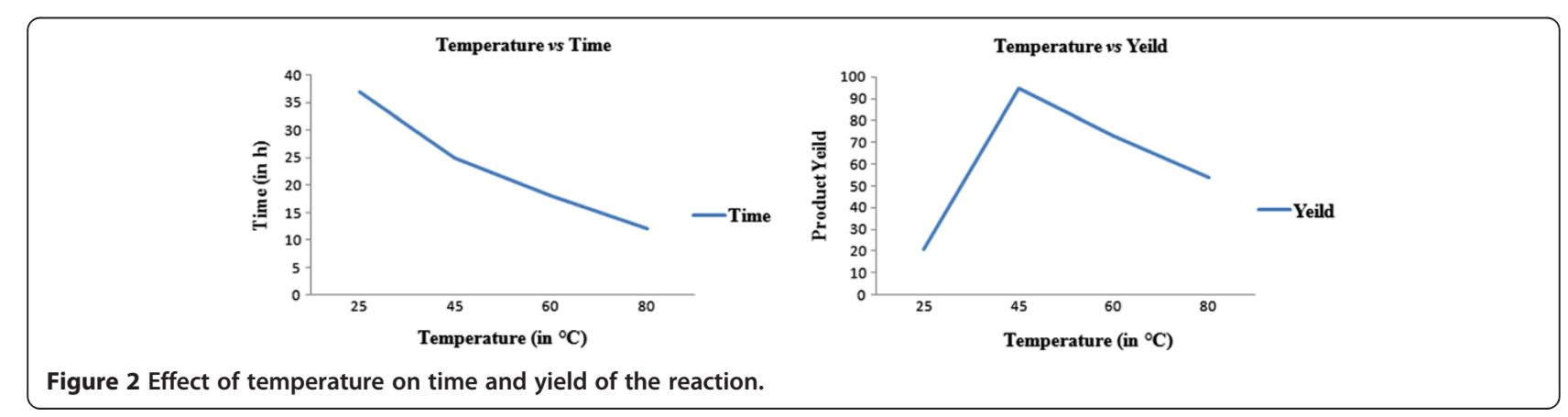


Table 3 Synthesis of highly functionalised 4-thiazolidinones catalysed by HLE
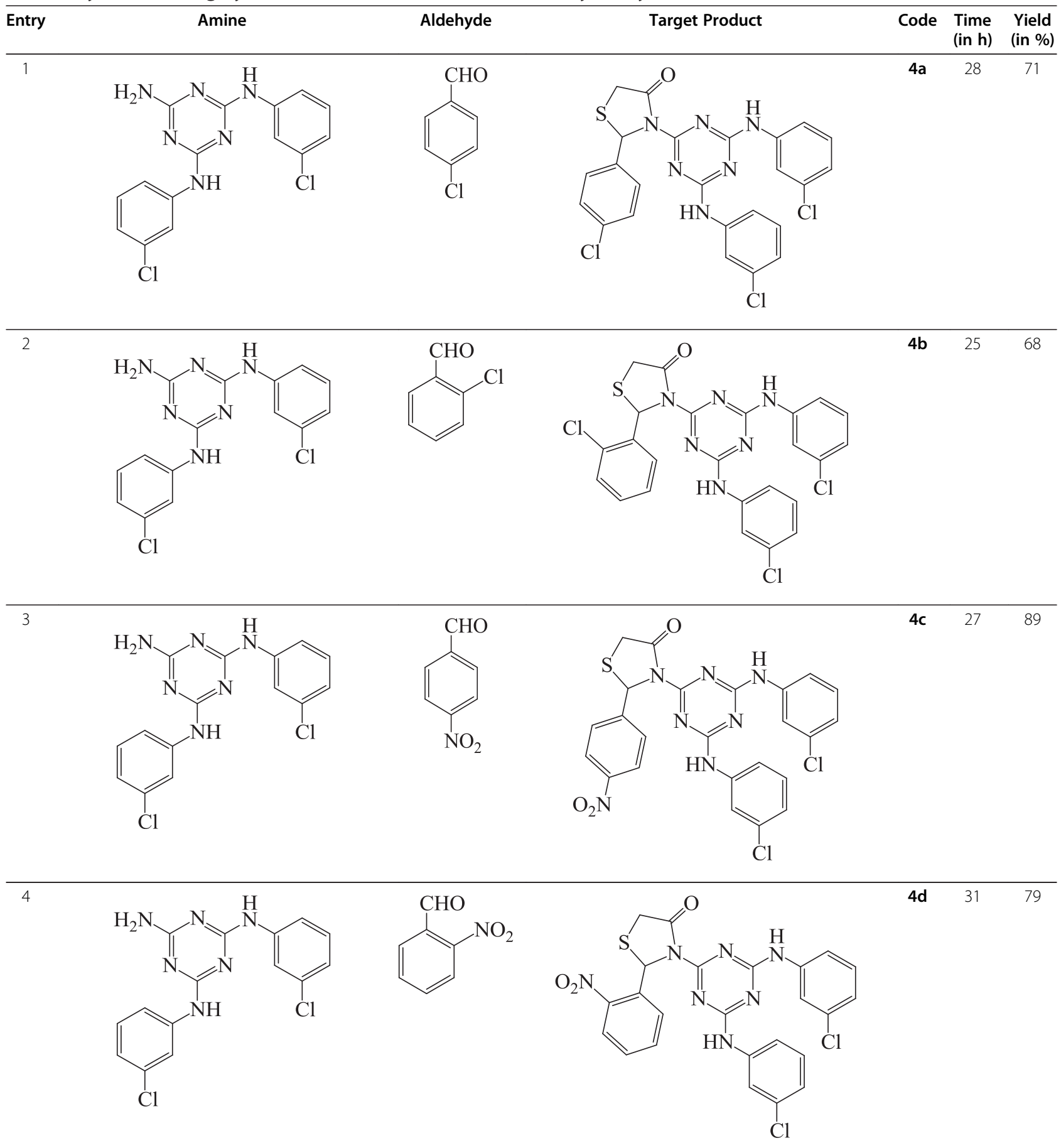


\section{Table 3 Synthesis of highly functionalised 4-thiazolidinones catalysed by HLE (Continued)}

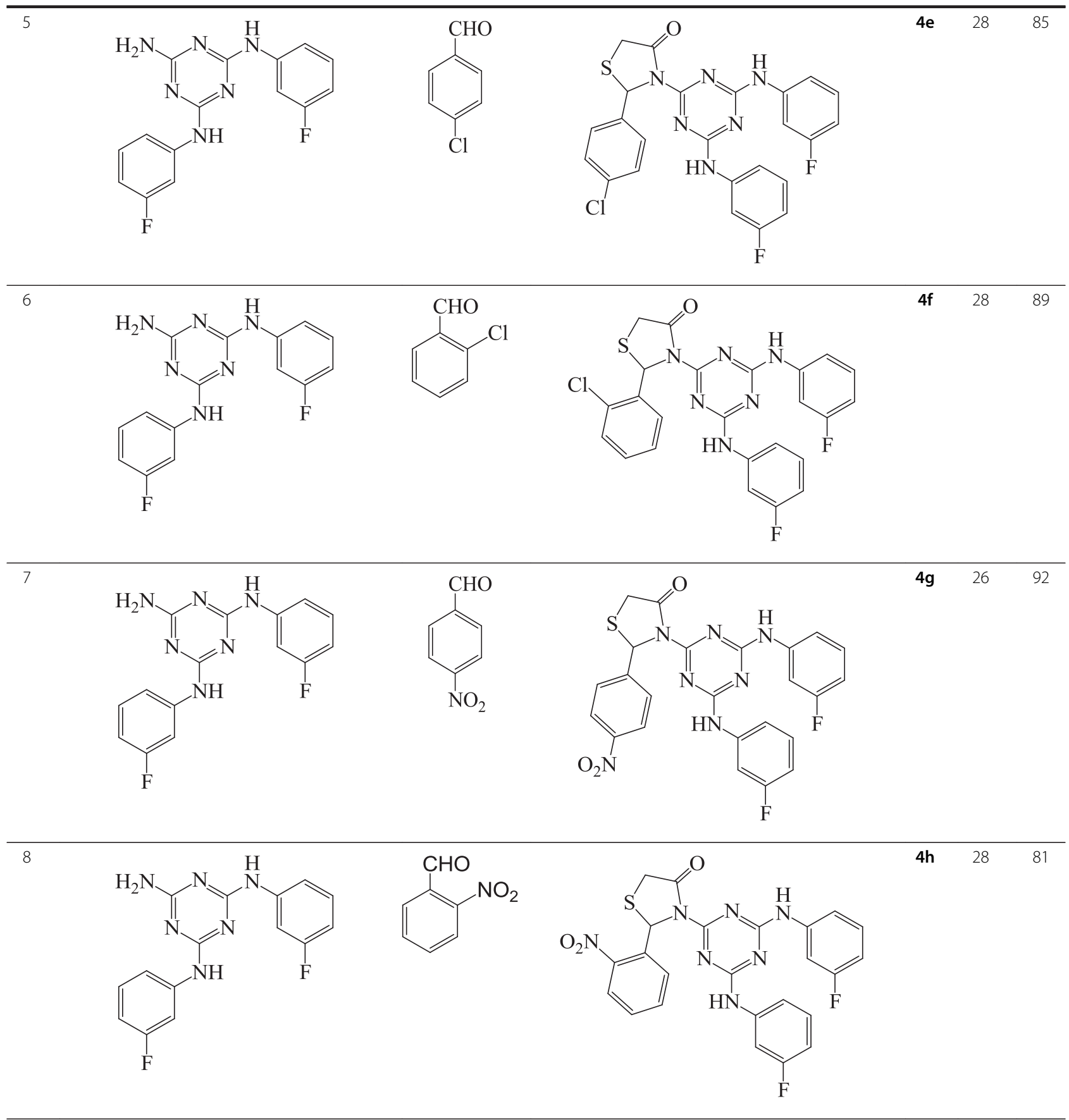




\section{Table 3 Synthesis of highly functionalised 4-thiazolidinones catalysed by HLE (Continued)}

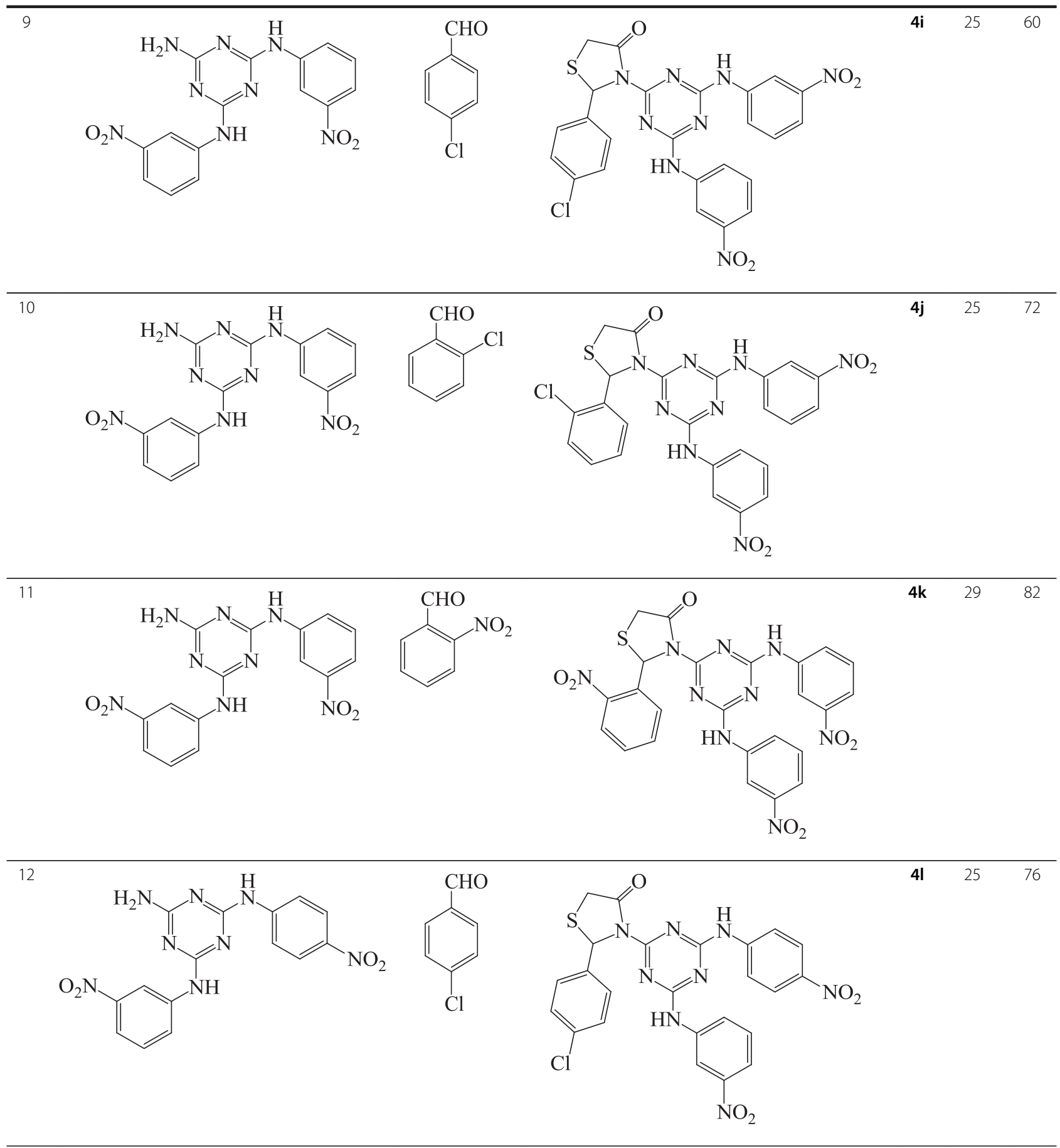




\section{Table 3 Synthesis of highly functionalised 4-thiazolidinones catalysed by HLE (Continued)}

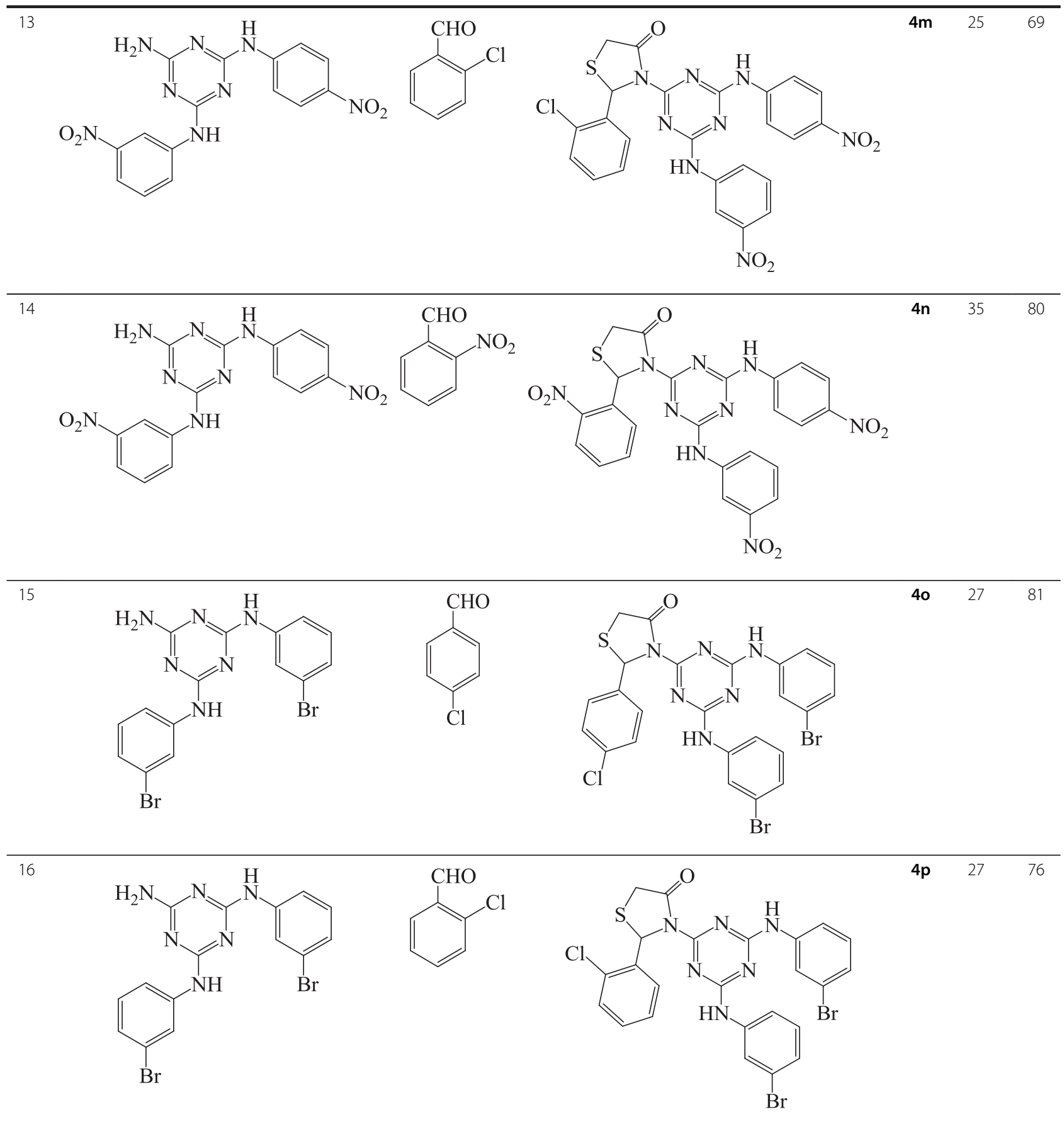


Table 3 Synthesis of highly functionalised 4-thiazolidinones catalysed by HLE (Continued)<smiles>Nc1nc(Nc2cccc(Br)c2)nc(Nc2cccc(Nc3nc(N)nc(Nc4cccc(Br)c4)n3)c2)n1</smiles>

and 1,3,5-triazine derivatives. Under standardised and similar set of reaction conditions, a series of 4thiazolidinone-1,3,5-triazine conjugates were obtained in fairly good yields ranging from $60-90 \%$. It is shown in Table 3, di-substituted $p$-chloro phenylamine-1,3,5triazine underwent smooth cyclization on treatment with isomeric chloro and nitro substituted aldehyde derivatives $4(\mathrm{a}-\mathrm{d})$. The compound containing $p$-nitro aldehyde resulted in high yield (4c, 89\%), while a drastic decrease in yield was observed with its ortho isomeric counterpart (4d, 79\%). Further drop in product yield was observed with chloro substituted aldehyde, the least being in the case of $o$-chloro derivative $(4 \mathrm{~b}, 68 \%)$. On introduction of fluoro in the place of chloro in 1,3,5-triazine by keeping aldehyde portion constant ( $4 \mathrm{e}-4 \mathrm{~h})$, a considerably high shift in product yield was observed varying from 81 $92 \%$, while the compound containing $o-\mathrm{NO}_{2}$ substituted aldehyde (4h) showed the lowest yield. However, a notable upward swing in yield was observed on changing the position of $\mathrm{NO}_{2}$ to $p$ - from $o$ - position on aldehyde (92\%). It is noteworthy to mention that introduction of non-halogen electron withdrawing group $\left(\mathrm{NO}_{2}\right)$ on diphenyl amine wings of 1,3,5-triazine along with isomeric chloro substituted aldehyde scaffold resulted in good yield of products (4i-4k). Further a slight increase in reaction time and product yield was observed on insertion of non-halogenated electron withdrawing group $\left(\mathrm{NO}_{2}\right)$ on aldehyde fragment $4 \mathrm{k}$. In the next instance, no substantial change in product yield and reaction condition was observed on altering the substitution pattern of $\mathrm{NO}_{2}$ to $p$ - position of the phenyl amine linked to 1,3,5-triazine with isomeric chloro substituted aldehydes (4l and $4 \mathrm{~m}$ ). The presence of three $\mathrm{NO}_{2}$ groups in the hybrid conjugate $(4 \mathrm{n})$ prolonged the reaction time to $35 \mathrm{~h}$ with marginal change in product yield. Further, presence of bromo group 4(o-r) would not significantly alter the product yield and reaction time. The structures of all newly compounds were ascertained on the basis of IR, ${ }^{1} \mathrm{H}$-NMR, ${ }^{13} \mathrm{C}-\mathrm{NMR}$ analysis and elemental analysis. The details has been shown in Additional file 1 .

It was inferred that halogen containing 1,3,5-traizine and aldehyde derivatives were well suited to this condensationcyclization reaction with varying reaction time \& yield to afford 4-thiazolidine-1,3,5-traizine hybrid conjugates. In general, the substitution on the aldehyde part was found as the main determinant for the reaction time and product yield. It was evident from Table 3 that the reaction proceeded well with aldehyde having the substitution far apart from the reaction centre, i.e., para positions $(4 \mathrm{a}, 4 \mathrm{c}$, $4 \mathrm{e}, 4 \mathrm{~g}, 4 \mathrm{i}$ and $4 \mathrm{l}$ ) and was not favoured with substitution near to reaction centre, i.e., ortho positions (4b, $4 \mathrm{~d}, 4 \mathrm{f}, 4 \mathrm{~h}$, $4 \mathrm{j}, 4 \mathrm{k}, 4 \mathrm{~m}$ and $4 \mathrm{n}$ ). The generation of steric hindrance due to the presence of substituent in the close proximity of reaction centre of aldehyde might be the probable cause of this observation.

The reaction catalysed by HLE was supposed to follow the classical pseudophase model of the micelles, which may also be called as two domain pseudophase model. It 


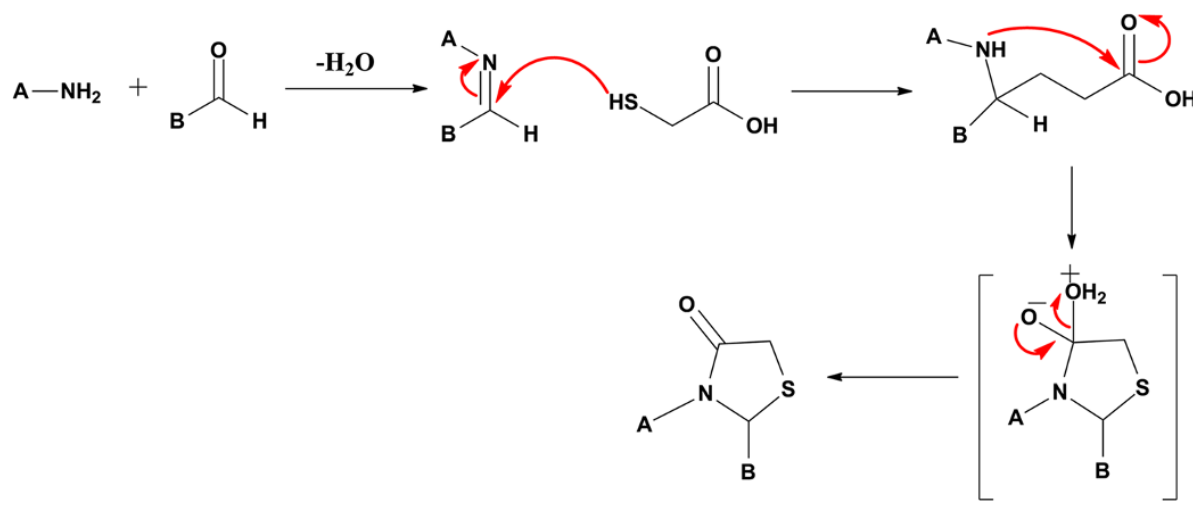

Figure 3 Mechanism of synthesis thiazolidine-4-one catalysed by HLE, where, A, is amine and B, is aldehyde fragment.

provided the micro-reactor medium for the catalysis. This suggested that the entire system was divided into two reaction domains, i.e., the bulk aqueous region and the entire micellar pseudophase. The reaction was believed to proceed in micellar pseudophase via imine formation (the nitrogen of amine attacks the carbonyl of aldehyde) in the first step followed by attack of sulphur nucleophile on the imine carbon and finally intramolecular cyclization with elimination of water molecule, Figure 3. It was also inferred that the yield of the product was increased on increasing the catalytic load accompanied by shorter reaction time, which may be attributed to increase in number of micelles with increasing concentration of surfactant, Table 1 (Romsted 1977; Jain et al. 2012). However, at an optimum micellar concentration (25 mol\%), in which the reactant molecules are almost completely micellized, the increase in micelle concentration (increasing the catalytic load to $50 \mathrm{~mol} \%$ ) does not affect the rate constant of the reaction but rather decreases the rate of the reaction, merely because of the dilution effect on the concentrations of micellized reactants, Figure 4 and serves as the probable cause of decrease in product yield.

\section{Experimental}

\section{General procedure for synthesis of title hybrid analogues} $4(a-n)$

To a solution of HLE (25 mol\%), amine (1, $0.01 \mathrm{~mol})$, aldehyde (2, $0.01 \mathrm{~mol})$ and thioglycolic acid (3, $0.01 \mathrm{~mol})$ were added successively at $45^{\circ} \mathrm{C}$ and the reaction mixture was stirred for time duration as reported in Table 3. After completion of the reaction, a saturated $\mathrm{NaHCO}_{3}$ solution was added followed by the addition of saturated brine solution. The product was extracted with ethyl acetate (3 times). The organic layers were combined, washed with water, dried over anhydrous sodium sulfate and evaporated under reduced pressure to dryness. Purification of crude product was carried out by column chromatography using silica gel (60-120 mesh size) via 10-30\% ethyl acetate in heptane as an eluent to furnish the desired product.

\section{Conclusion}

As a concluding remark, for the first time home laundry effluent (HLE) owing to the surfactant like property has been successfully utilised as catalyst for the synthesis of a series of novel 4-thiazolidinone derivatives through one pot, three component condensation-cyclization reaction. The uniqueness of the present protocol lies in the operational simplicity, ability to reduce the demand for organic solvents, reduce the energy and carbon footprint, and meeting a wide range of economic needs. However, the investigations of the characterisation of HLE as catalyst and medicinal properties of these novel compounds are still underway and will be reported in due course of time.
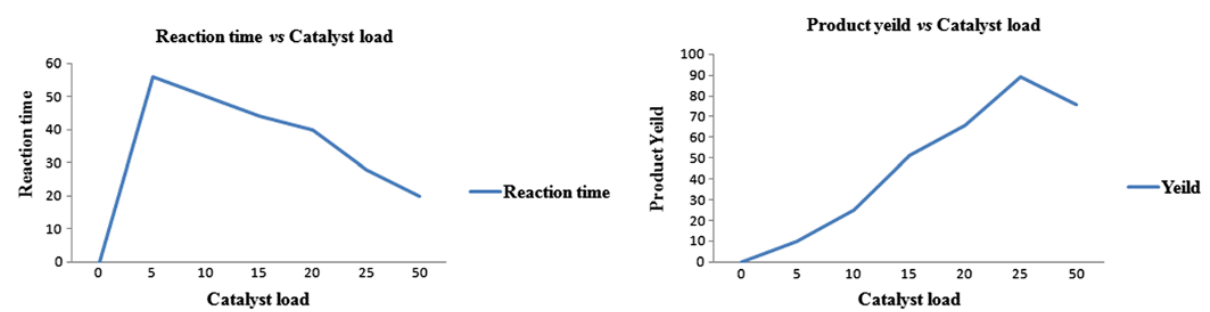

Figure 4 Effect of catalyst load on reaction time and catalyst load. 


\section{Additional file}

\section{Additional file 1: Experimental details and spectroscopic data of} final compounds 4 (a-n).

\section{Competing interests}

The authors declare that they have no competing interests.

\section{Authors' contribution}

The current study is an outcome of constructive discussion betwean UPS and RKS. UPS carried out the synthesis and characterizations were carried by UPS, HRB and MKK. They were also involved in the drafting of the manuscript. UPS and RKS were involved in revising the manuscript. All authors read and approved the final manuscript.

\section{Acknowledgements}

Authors are thankful to SAIF, Punjab University, India and SHIATS, India for providing spectroscopic data of compounds synthesized herein necessary infrastructural facilities, respectively.

\section{Author details}

${ }^{1}$ Department of Pharmaceutical Sciences, Sam Higginbottom Institute of Agriculture Technology and Sciences, Formerly Allahabad Agricultural Institute, Deemed to be University, Allahabad 211007, India. ${ }^{2}$ Anand College of Pharmacy, Agra 282007, India. ${ }^{3}$ Nucleic Acids and Antiviral Research Laboratory, Department of Chemistry, University of Allahabad, Allahabad 211002, India.

Received: 30 April 2013 Accepted: 9 September 2013

Published: 16 September 2013

\section{References}

(2012) , http://www.epa.gov/greenchemistry/, Accessed on Dec 28

Ariel, a laundry detergent (washing powder) used as surfactant source, product made in India by Procter and Gamble home products Ltd. Mumbai 400099, the common Laundry detergent contains alkylbenzenesulfonates. For this reaction, washed over effulent from the home washing machine of daily use clothes like shirts, pants, scarf's and etc. in mild dirty condition was selected, this liquid was further filtered to remove any solid particles before using as reaction media

Allen L, Christian-Smith J, Palaniappan M (2010) Overview of greywater reuse: the potential of greywater systems to aid sustainable water management. Pacific Institute, California USA

Bekircan O, Küxük M, Kahveci B, Kolayli S (2005) Convenient synthesis of fused heterocyclic 1,3,5-triazines from some $\mathrm{N}$-acyl imidates and heterocyclic amines as anticancer and antioxidant agents. Archiv der Pharmazie 338:365-372, doi:10.1002/ardp.200400964

Bhat HR, Singh UP, Gahtori P, Ghosh SK, Gogoi K, Prakash A, Singh RK (2013) Antimalarial activity and docking studies of novel bi-functional hybrids derived from 4-aminoquinoline and 1,3,5-triazine against wild and mutant malaria parasites as pf-DHFR inhibitor. RSC Adv 3:2942-2952, doi:10.1039/C2RA21915H

Bolognese A, Correale G, Manfra M, Lavecchia A, Novellino E, Barone V (2004) Thiazolidin-4-one formation. Mechanistic and synthetic aspects of the reaction of imines and mercaptoacetic acid under microwave and conventional heating. Org Biomol Chem 2:2809-2813, doi:10.1039/B405400H

Dubey V, Bhat HR, Singh UP (2012) Design, facile synthesis, and antibacterial activity of hybrid 1,3,4-thiadiazole-1,3,5-triazine derivatives tethered via -S- bridge. Chem Biol Drug Des 80:598-604, doi:10.1111/j.1747-0285.2012.01433.x

Dunn P (2010) Water as a Green Solvent for Pharmaceutical Applications. Handbook of Green Chemistry 5:363, doi:10.1002/9783527628698.hgc058

El Bialy SA, Nagy MM, Abdel-Rahman HM (2011) Efficient regioselective threecomponent domino synthesis of 3-(1,2,4-Triazol-5-yl)-1,3-thiazolidin-4-ones as potent antifungal and antituberculosis agents. Archiv der Pharmazie 344:821-829, doi:10.1002/ardp.201100001

El-Aal RMA (2003) Spiro-Azoles Thiazolidinone in the Synthesis of Polymethine Cyanine Dyes. Phosphorus, Sulfur Silicon Relat Elem 178:681-692, doi:10.1080/10426500307791
Eleftheriou P, Geronikaki A, Hadjipavlou-Litina D, Vicini P, Filz O, Filimonov D, Poroikov V, Chaudhaery SS, Roy KK, Saxena AK (2012) Fragment-based design, docking, synthesis, biological evaluation and structure-activity relationships of 2-benzo/benzisothiazolimino-5-aryliden-4-thiazolidinones as cycloxygenase/lipoxygenase inhibitors. Eur J Med Chem 47:111-124, doi:10.1016/j.ejmech.2011.10.029

Fuchigami T, Narizuka S, Konno A (1992) Electrolytic partial fluorination of organic compounds. 4. Regioselective anodic monofluorination of 4-thiazolidinones and its application to the synthesis of monofluoro.beta.lactams. J Org Chem 57:3755-3757, doi:10.1021/jo00040a003

Gahtori P, Ghosh SK (2012) Design, synthesis and SAR exploration of hybrid 4-chlorophenylthiazolyl-s-triazine as potential antimicrobial agents. J Enzyme Inhib Med Chem 27:281-293, doi:10.3109/14756366.2011.587418

Ghosh SK, Saha A, Hazarika B, Singh UP, Bhat HR, Gahtori P (2012) Design, facile synthesis, antibacterial activity and structure-activity relationship of novel diand tri-substituted 1,3,5-triazines. Lett Drug Des Dis 9:329-335, doi.org/10.2174/157018012799129846

Havrylyuk D, Kovach N, Zimenkovsky B, Vasylenko O, Lesyk R (2011) Synthesis and anticancer activity of isatin-based pyrazolines and thiazolidines conjugates. Archiv der Pharmazie 344:514-522, doi:10.1002/ardp.201100055

Jain AK, Vaidya A, Ravichandran V, Kashaw SK, Agrawal RK (2012) Recent developments and biological activities of thiazolidinone derivatives: A review. Bioorg Med Chem 20(11):3378-3395, doi:10.1016/j.bmc.2012.03.069

Kumar S, Bhat HR, Kumawat MK, Singh UP (2013) Design and one-pot synthesis of hybrid thiazolidin-4-one-1,3,5-triazines as potent antibacterial agents against human disease-causing pathogens. New J Chem 37:581-584, doi:10.1039/C2NJ41028A (a) Verma A, Saraf SK (2008) 4-thiazolidinone-a biologically active scaffold. Eur J Med Chem 43: 897-905. doi.org/10.1016/j.ejmech.2007.07.017

Lindstrom UM (2002) Stereoselective organic reactions in water. Chem Rev 102:2751-2772, doi:10.1021/cr010122p

Lozano V, Aguado L, Hoorelbeke B, Renders M, Camarasa MJ, Schols D, Balzarini J, San-Félix A, Pérez-Pérez MJ (2011) Targeting HIV entry through interaction with envelope glycoprotein 120 (gp120): synthesis and antiviral evaluation of 1,3,5-triazines with aromatic amino acids. J Med Chem 54:5335-5348, doi:10.1021/jm200560r

Morphy R, Rankovic Z (2005) Designed multiple ligands.An emerging drug discovery paradigm. J Med Chem 48:6523-6543, doi:10.1021/jm058225d

Orru RVA, de Greef M (2003) Recent Advances in Solution-Phase Multicomponent Methodology for the Synthesis of Heterocyclic Compounds. Synthesis 10:1471-1499, doi:10.1055/s-2003-40507

Prasad D, Preetam A, Nath M (2012) DBSA catalyzed, one-pot three-component "on water" green protocol for the synthesis of 2,3-disubstituted 4-thiazolidinones. RSC Adv 2:3133-3140

Rawal RK, Prabhakar YS, Katti SB, De Clercq E (2005) 2-(Aryl)-3-furan-2-ylmethylthiazolidin-4-ones as selective HIV-RT inhibitors. Bioorg Med Chem 13:6771-6776, doi.org/10.1016/j.bmc.2005.07.063

Romsted LS (1977) "Micellization Solubilsation and Microemulsions", vol II. K.L. Mittal Plenum Press, New York, p 509

Shapiro N, Vigalok A (2008) Highly Efficient Organic Reactions "on Water", "in Water", and Both. Angewandte Chemie 120:2891-2894, doi:10.1002/ange.200705347

Siddiqui N, Arshad MF, Khan SA, Ahsan W (2010) Sulfonamide derivatives of thiazolidin-4-ones with anticonvulsant activity against two seizure models: synthesis and pharmacological evaluation. J Enzyme Inhib Med Chem 25:485-491, doi:10.3109/14756360903282833

Singh UP, Singh RK, Bhat HR, Subhaschandra YP, Kumar V, Kumawat MK, Gahtori $P$ (2011) Synthesis and antibacterial evaluation of series of novel trisubstituted-s-triazine derivatives. Med Chem Res 20:1603-1610, doi:10.1007/s00044-010-9446-7

Singh UP, Bhat HR, Gahtori P (2012a) Antifungal activity, SAR and physicochemical correlation of some thiazole-1,3,5-triazine derivatives. J Mycol Méd 22:134-141, DOI: 10.1016/j.mycmed.2011.12.073

Singh UP, Pathak M, Dubey V, Bhat HR, Gahtori P, Singh RK (2012b) Design, synthesis, antibacterial activity, and molecular docking studies of novel hybrid 1,3-thiazine-1,3,5-triazine derivatives as potential bacterial translation inhibitor. Chem Biol Drug Des 80:572-583, doi:10.1111/j.1747-0285.2012.01430.x

Surrey AR (1947) The preparation of 4-thiazolidones by the reaction of thioglycolic acid with Schiff bases. J Am Chem Soc 49:3105-3107, doi:10.1021/ja01177a048

Tierney J (1989) The formation of 2,3-disubstituted thiazolidin-4-ones from s-a'aminomercaptoacetic acid derivatives. J Heterocyclic Chem 26:997-1001, doi:10.1002/jhet.5570260419 
Turgut Z, Yolacan C, Aydogan F, Bagdatli E, Ocal N (2007) Synthesis of New Pyrazolothiazole Derivatives from 4-Thiazolidinones. Molecules 12:2151-2159, doi:10.3390/12092151

Wrobel J, Jetter J, Kao W, Rogers J, Di L, Chi J, Peréz MC, Chen GC, Shen ES (2006) 5-Alkylated thiazolidinones as follicle-stimulating hormone (FSH) receptor agonists. Bioorg Med Chem 14:5729-5741, doi.org/10.1016/j.bmc.2006.04.012

Zevzikoviene A, Zevzikovas A, Tarasevicius E, Pavlonis A, Dirse V (2012) Synthesis and in vitro antimicrobial study of 4-thiazolidinone containing sulfanilamide. Acta Poloniae Pharmaceutica 69:911-915

Zhao S, Cheng M, Li J, Tian J, Wang X (2011) One pot production of 5hydroxymethylfurfural with high yield from cellulose by a Brønsted-Lewissurfactant-combined heteropolyacid catalyst. Chem Commun (Camb) 47:2176-2178, doi:10.1039/c0cc04444j

doi:10.1186/2193-1801-2-466

Cite this article as: Singh et al:: Utilisation of Home Laundry Effluent (HLE) as a catalyst for expeditious one-pot aqueous phase synthesis of highly functionalised 4-thiazolidinones. SpringerPlus 2013 2:466.

\section{Submit your manuscript to a SpringerOpen ${ }^{\circ}$ journal and benefit from:}

- Convenient online submission

- Rigorous peer review

- Immediate publication on acceptance

- Open access: articles freely available online

- High visibility within the field

- Retaining the copyright to your article 